\title{
Laboratories of democracy: the collision of federal and local global warming policy in the United States
}

\author{
J. Manko
}

Manko, Gold, Katcher \& Fox, LLP, USA

\begin{abstract}
Scientists have reached a consensus that global warming is a reality and human emissions of greenhouse gases are affecting the climate. As the negative effects of global warming become more certain and more pervasive, the federal government of the United States has, to date, largely refused to take action. Hurricane Katrina (2005) and its aftermath not only provide a case study of the federal government's failure to take positive steps, but also its tendency to make regressive policy decisions on global warming. At the state, local and individual level, however, the problem of greenhouse gas emissions is beginning to receive the attention it deserves. As pressure for action mounts, the conflicting federal and local views have now reached the courts. The U.S. Supreme Court has decided to hear a case, brought by petitioning states, cities and public interest groups, demanding that the federal government regulate greenhouse gas emissions. Although this will be an important case, it is unlikely that the local interests will prevail and even a victory for the petitioners would have only a limited effect. The more important meaning of the case is an acknowledgement by at least one branch of the federal government that state and local pressures to take action to limit greenhouse gas emissions can no longer be ignored. Comprehensive action on greenhouse gas emissions in the U.S. must come from the executive and legislative branches.
\end{abstract}

Keywords: law, global warming, greenhouse gas emissions, United States environmental policy. 


\section{Introduction}

The scientific case for the existence of human-made climate change has now been established (Karl et al. [1]). Scientists have catalogued a wide range of phenomena caused by global warming within the United States alone (Parmesan and Galbraith [2]). Although scientific efforts must continue to observe, define and quantify climate change, global warming can no longer be discounted as a purely scientific phenomenon or an academic question. Scientific and technological breakthroughs will be indispensable to combat its problems, but these breakthroughs may never be implemented, or perhaps even attempted, without sufficient support from governments throughout the world. In the twenty-first century and beyond, global warming cannot be stopped through science alone; it must be stopped by sound environmental policy on a global scale.

The Vermont Environmental Law Center describes good environmental policy as "represent[ing] affirmative decisions to protect natural systems from the impact of human activities. Such policy must be formed at the intersection of politics, law, science, economics and ethics." Thus, good environmental policy requires input not only from scientists; it also requires the work of lawyers, politicians, businesspersons and private citizens. This paper will investigate the political and legal struggles to develop good global warming policy in the United States.

\section{Pre-Katrina U.S. federal policy on global warming}

The defining element of the U.S. government's policy on global warming - both before Hurricane Katrina and at present - is the refusal to implement the Kyoto Protocol to the United Nations Framework Convention on Climate Change ("Kyoto Protocol"). While former Vice-President Al Gore symbolically signed the Kyoto Protocol in 1998, neither the Clinton nor Bush administrations presented the treaty to the Senate for ratification. President Bush has made it clear that he will not sign Kyoto because of its cost to the U.S. economy and its failure to regulate developing countries such as India and China, other major greenhouse gas emitters. Despite the U.S. refusal to ratify the treaty, the Kyoto Protocol came into effect in February 2005. The U.S.'s status as the largest emitter of greenhouse gasses makes its failure to participate extremely damaging to the overall goals of Kyoto.

Greenhouse gas emissions and global warming have not been entirely ignored by the federal government. The Energy Policy Act of 2005, signed into law by President Bush, contained funding for the development of renewable energy sources that do not emit greenhouse gases and an initiative to increase the amount of clean-burning ethanol used in the U.S. Perhaps more importantly, the enacted legislation deleted several provisions from the original bill that would have relaxed Clean Air Act regulations on power plants and permitted drilling for oil within the Alaskan National Wildlife Refuge. 
Although the Energy Policy Act of 2005 did not ignore global warming, many contend that the provisions cited above merely paid lip service when taken in context with the bill as a whole. The funding for renewable energy sources in the bill was dwarfed by the funding provided for traditional energy sources such as oil and coal. Provisions calling for Kyoto-like regulation of greenhouse gas emissions in the U.S. in the original bill were completely excised from the enacted legislation.

\section{Katrina as a case study of federal global warming policy}

There is a scientific consensus that rising temperatures in the tropical Atlantic Ocean are responsible for the increased violence of hurricanes over the past decade. A recent study supported by the U.S. National Science Foundation finds that global warming, and not natural fluctuations, is causing this temperature increase (Trenberth and Shea [3]). If human activity is indeed raising ocean temperatures, then the United States is already suffering the first adverse affects of global warming.

The 2005 Atlantic hurricane season had several record-setting storms, including the most destructive storm of all time, Katrina, and the most intense storm ever to hit the Gulf of Mexico, Rita (Nesmith [4]). Many hoped that Katrina's devastation would serve as a "canary in the mineshaft," alerting the federal government that it must take immediate action to limit greenhouse gas emissions. The reality of the situation is the exact opposite - the federal government has ignored the warning and its actions in the wake of Katrina have actually been counterproductive. The federal government's response to Katrina provides a case study of regressive policies on global warming.

It is important to note here that this critique of current U.S. federal policy does not suggest that the current administration, or even the U.S. as a whole, is in some way "responsible" for Hurricane Katrina. It is impossible to assign global warming as the cause of any individual hurricane. Furthermore, the causes and possible consequences of global warming existed and had been noted scientifically by the end of the nineteenth century. Assigning blame to an administration that has been in power for roughly six years, regardless of its policy decisions, would be unfair.

Although the federal government's inadequate emergency response to Katrina has been strongly criticized, the regressive response reflected in federal energy policy is equally troubling. If the harrowing images of destruction provided by Katrina result in the government actually decreasing regulation of greenhouse gas emissions, it is hard to imagine the evidence necessary to spur responsible change.

In the aftermath of Katrina and Rita, federal policymakers were not concerned with the possible causes of the unusually destructive hurricane season; they were concerned with its effects on traditional, petroleum-based U.S. energy supplies. Katrina and Rita damaged the U.S. capacity to refine oil, and this and other factors resulted in a huge increase in energy prices, especially prices at the pump for gasoline consumers. 
As a result, the immediate response of the U.S. Environmental Protection Agency ("EPA") to Katrina was the temporary waiver of gasoline and diesel fuel standards in Louisiana, Mississippi, Alabama and Florida. More limited waivers were issued to the other 46 states. A bill was introduced in the Senate that would have granted the EPA administrator authority to waive any regulation for purposes of disaster recovery or if he considered it to be in the public interest. The bill never reached the Senate floor for a vote.

Similarly, the U.S. House of Representatives' immediate response was to pass the "Gasoline for American Security Act," commonly called the GAS Act, to encourage increased refining capacity in the U.S. Opponents alleged that the bill was a handout to gasoline companies, would result in more emissions and dirtier skies, and was essentially an attempt to push through, under the auspices of national security, policies rejected from the aforementioned Energy Policy Act of 2005. The House narrowly passed the bill over vigorous opposition, but the Senate has yet to take action on the bill.

In a surprising about-face, President Bush declared in his 2006 State of the Union Address that the country was "addicted to oil" and promised to increase efforts to find renewable sources of energy. His specific pledge to cut imports of foreign oil by 75 percent before 2025 was most striking. The very next day, however, the U.S. energy secretary and national economic adviser announced that the President had not really meant what he said - rather, the United States would always import oil from the Middle East and the President's statements had been "merely an example" (Neikirk and Martin [5]).

More recently, the Bush administration has congratulated itself on its efforts to limit greenhouse gas emissions. The cause for celebration was not a decrease in the amount of U.S. emissions, but merely a decrease in the rate at which emissions were increasing. Such a position ignores the international consensus, enshrined in the Kyoto Protocol, that stabilizing the global climate requires a reduction in the amount of greenhouse gas emissions far below current levels.

There are some sources of hope within the federal government. Most notably, the U.S. Senate passed a resolution in 2005 calling for a program to regulate greenhouse gas emissions. A resolution, which has no binding effect, is far from the comprehensive regulatory program some would desire, but it is far better than the increasing deregulation of emissions seemingly favored by the U.S. House of Representatives.

\section{State and regional responses}

The U.S. is often seen by the rest of the world as a monolithic political entity embodied by its President. The political reality of the U.S. federal system is far more complex than this view suggests. Many of the foregoing examples of regressive policy were vigorously opposed by numerous states and cities. As an example, perhaps the least responsible bill, the GAS Act, was objected to strenuously by the National League of Cities, the United States Conference of Mayors and the Environmental Council of the States - all national organizations representing state and local interests. 
While the international community attempts to exert pressure on the U.S. from without, the most likely source of change will be the pressure from within. Some leverage derives from traditional public interest groups with environmental agendas, but increasingly it comes from individual states and cities. To some extent, states and cities have sought to pressure the federal government by filing lawsuits discussed later in the paper. In addition, states and cities have begun to step into the regulatory role that the federal government has largely declined to play.

Perhaps the most important regulatory effort is an agreement between several eastern states that has been described as a "mini-Kyoto." (Globe Editorial [6]) The Regional Greenhouse Gas Initiative ("RGGI") seeks to create a cap-andtrade market for carbon dioxide allowances starting in 2009. Disagreements over implementation of the program have slowed its progress and caused two states (Rhode Island and Massachusetts) to drop out. Critics cite as major problems the RGGI's failure to regulate greenhouse gasses other than carbon dioxide, its sole focus on power plants, and the possibility of leakage (i.e. states importing "dirty" energy from outside the region). Despite these real concerns, the RGGI remains the most serious attempt to regulate greenhouse gas emissions in the U.S.

On the west coast, California is leading efforts to limit greenhouse gas emissions. Although some plans in California may be further from implementation than the RGGI, they exceed the eastern states' efforts in both breadth of regulation and public support. California has already demonstrated its commitment to this issue by passing restrictive regulations on automobile emissions. Spurred by California Governor Schwarzenegger's 2005 executive order establishing targets for emissions reduction, state lawmakers have introduced comprehensive legislation on greenhouse gas emissions. The program would create an emissions trading program similar to RGGI, but not limited to power plants. It would also create mandatory emissions reporting and a requirement that all new energy generated in the state come from sources with greenhouse gas emissions less than or equal to efficient modern power plants. While public support for the legislation appears to be high, there is some concern that the bill will be severely modified before passage due to industry pressure.

California has also stepped onto the international stage on global warming issues. In August 2006, Governor Schwarzenegger met with British Prime Minister Tony Blair to announce an agreement between the two governments. The collaboration's practical extent is limited to the exchange of information. While the move is viewed as largely symbolic, the agreement between a U.S. state and a foreign government is an unprecedented attempt to circumvent the federal government's lack of engagement on this issue at the international level.

In America's federal system, states are often described as "laboratories" for federal policy. If the experiments conducted by California and the RGGI are successful at curbing emissions while not unduly damaging state and regional economies, their example would undercut much of the opposition to a national regulatory scheme. Although state and regional actions can never be satisfactory 
substitutes for federal action, they can serve as both proof-of-concept and a model framework for a comprehensive national program.

\section{Business and industry responses}

One surprising source of positive change has been industry itself. In the past, efforts from some industry sectors appeared to focus on minimizing the climate change problem and maintaining a positive public image. For instance, during the Kyoto negotiations, an industry group known as the Global Climate Coalition spent millions of dollars on advertising downplaying the effects of global warming. In 2002, the coalition was disbanded after major members such as Ford, General Motors and Texaco became convinced that global warming was a reality and left the group. One former member, BP Amoco, has become an industry leader in reducing greenhouse gas emissions and joined the Pew Center on Global Climate Change Business Environmental Leadership Council ("BELC"), a group of businesses committed to fighting global warming.

The members of BELC are taking steps to address global warming of their own accord, without prompting from the federal government. Because its members are multinational companies, BELC can take its efforts beyond the U.S. and onto the international stage. While the U.S. and the European Union have so far been unable to reach an understanding on global warming, many U.S. and European companies have bridged the ideological gap. As the U.S. companies take it upon themselves to comply with international regulations, European companies have begun to seek an international market-based approach with which some European nations take issue, but the U.S. would prefer.

Efforts to decrease greenhouse gas emissions have not been limited to BELC. Many more companies have entered into compliance with voluntary programs administered by the federal government. In the newest data from these efforts, the 226 companies participating in one program lowered their 2004 emissions by three percent from the previous year. While the information from these voluntary regulatory programs has been positive, some continue to cite the obvious problems with any voluntary system: participation is limited and some participants do not rigorously follow the program.

The realities of regional and international regulatory programs force many companies to adopt emissions-limiting policies above and beyond those suggested by voluntary federal programs. As regional emissions restrictions emerge in the U.S., companies that do business on the national level are forced to consider programs to limit emissions for at least some of their operations. Multinational companies face another source of regulation to the extent their international operations are regulated by the Kyoto Protocol. Some companies, such as $3 \mathrm{M}$, respond to these dual pressures by implementing company-wide and therefore global - policies on greenhouse gas emissions.

The shift in industry attitude about global warming is a welcome development. Although many businesses may initially engage in these efforts to improve their public image and, for large companies, to comply with international regulations, they are also driven by the simple economic motive 
that drives most business decisions: making a profit. As companies have accepted the reality of global warming as a concern for their financial future, they have begun to adopt methods for dealing with it as they would for any other threat to business (Pew Center on Global Climate Change-BELC [7]). Against this backdrop, the continual downplaying of global warming by the federal government and its characterization of emissions regulations as "bad for the economy" appears even more insupportable when contrasted with the acceptance of its reality by these profit-driven entities.

\section{Collision in the Courts}

Louis Brandeis, the late U.S. Supreme Court Justice, introduced the metaphor of states as laboratories. Justice Brandeis wrote "a single courageous state may, if its citizens choose, serve as a laboratory; and try novel social and economic experiments without risk to the rest of the country" (New State Ice Co. v. Liebmann [8]). This metaphor for America's federal system has been an enduring one. Today, however, some states are dissatisfied with their role as laboratories and instead intend to serve as soldiers on the front line, attacking the federal government's interpretation of its own responsibilities under federal law. The final battleground for these disputes will almost certainly be the U.S. Supreme Court.

The Supreme Court recently announced it would hear an appeal in a case brought by several states, cities and public interest groups seeking to force the federal government to regulate greenhouse gas emissions. In Massachusetts v. $E P A$, the U.S. Circuit Court of Appeals for the District of Columbia found that EPA acted within the law in refusing to regulate these gases, but the Supreme Court's decision to hear the appeal means the high court will have the final word in this dispute (Massachusetts v. EPA [9]).

This decision to hear the case provides a reason for those concerned about global warming to take heart - the federal courts have previously been responsive to concerns about EPA shirking its duty to regulate emissions. For example, in New York v. EPA, a coalition of 14 states and several cities challenged EPA's attempt to loosen regulations on old power plants (New York v. EPA [10]). In March 2006, a federal appeals court ruled that EPA's position violated the Clean Air Act. The court delivered a stinging rebuke to EPA, declaring the agency's interpretation reasonable only in a "Humpty Dumpty world" [10]. This was a major victory for states, cities and public interest groups.

On the other hand, there are also reasons to be extremely concerned about the possible outcome. The makeup of the U.S. Supreme Court changed recently by President Bush's appointment of two conservative judges to fill vacant seats. The new Court has already handed down its first environmental decision in a case regarding the protection of wetlands, in which both new Justices joined the opinion that would have severely limited wetlands protection. The Court overall, however, was so divided that it could not issue a majority opinion and simply remanded the case for further consideration by the lower courts. Although it is 
difficult to characterize the Court generally or to predict its decision in the upcoming case, it would certainly be a mistake to view the current Court as proenvironment.

The resolution of the lower court case from which the Massachusetts v. EPA appeal springs should also be cause for concern. The three-judge panel hearing the case issued three separate opinions [11]. One judge would have dismissed the case on its merits, finding EPA's decision not to regulate greenhouse gases legally permissible. A second would have dismissed the case for a lack of standing - a jurisdictional issue - because the plaintiffs had not been "injured" by EPA's decision. The final judge found EPA's interpretation of the Clean Air Act impermissible and would have required EPA to regulate greenhouse gas emissions. The result of these separate opinions was a dismissal of the case and the subsequent appeal to the Supreme Court. What concerns environmentalists is the existence of two legal theories upon which to dismiss the suit, and only one on which to find for the plaintiffs. If the Supreme Court splits along the same lines the suit will be dismissed.

In the end, the entire suit may be dismissed for a lack of standing. Standing is often thought of as a legal technicality, but here it provides insight into the nature of the conflict the U.S. faces. Under the U.S. Constitution, a lawsuit may only be brought if the plaintiff has suffered a "particularized" injury. As the appeals court in Massachusetts v. EPA noted: "[A] plaintiff raising only a generally available grievance about government - claiming only harm to his and every citizen's interest in proper application of the Constitution and laws, and seeking relief that no more directly and tangibly benefits him than it does the public at large - does not [have standing]" [10].

The doctrine of standing defines the proper role of the courts in the U.S. - to redress injuries suffered by individuals. A rejection of this claim based on a lack of standing is not a statement that no problem exists. Instead it means that a problem of this magnitude, affecting every individual in the U.S. and on the planet, should not be redressed in a court of law, but rather must be addressed by the Congress as a political matter. Common-sense takes us one step further than the doctrine of standing: when a problem affects everyone on the planet, it must be addressed by the world as a whole.

Even a victory by the plaintiffs in this case would have a relatively small impact on greenhouse gas emissions in the U.S. The plaintiffs' claim is limited to one section of the Clean Air Act dealing with automobile emissions, and thus would not affect power plants or other sources of emissions. It also seems certain that today's EPA would, if forced, adopt the least stringent restrictions on emissions that would satisfy the Court, and those restrictions would likely be slow in coming.

\section{International legal responses}

Some environmentalists view international law as another avenue for legal challenges to U.S. policy. One example is a recent petition filed with the InterAmerican Commission on Human Rights. The petition, filed by a group 
representing the inhabitants of the Arctic Circle, seeks a declaration that U.S. refusal to regulate greenhouse gas emissions represents a violation of their human rights (Choo [11]). The likely impact of the petition is limited, as it does not seek damages, although a favorable ruling could theoretically ground tort claims against the U.S.

At the present time, international legal action remains, like the petition, a largely theoretical method of influencing the federal government, and there are serious questions about its possible efficacy. One reason for this is that the U.S. has not ratified the treaty creating the International Court of Justice. As such, an opinion from that court could only express international displeasure at U.S. policy. Most international legal efforts will suffer from the same limitation, and the U.S. has made clear in the past it is willing to buck international opinion on the issue of global warming.

\section{Conclusion}

The hope inspired by the Supreme Court's decision to hear Massachusetts $v$. $E P A$ is not misplaced, but it may spring from the wrong sources. It is true that sound global warming policy is not purely scientific, and its implementation will not be achieved solely through technology. Supreme Court watchers must realize, however, that good environmental policy is also not purely legal and no court can ever provide the solution.

The Supreme Court's decision to hear a case involving greenhouse gas emissions is a reason to hope because it represents an acknowledgement, by a branch of the federal government, that state, local and public opinion can no longer be ignored on this issue. Any real step towards good environmental policy on global warming in the U.S. will have to come from the U.S. Congress and the president. But as pressure mounts to do something about greenhouse gas emissions, the political resistance to regulation will become weaker and weaker. While the federal courts have provided a venue for state and local interests to make their demands felt, the final battleground on this issue will lie within the legislative and executive branches. Thus, the congressional elections in November 2006, and the presidential election in November 2008, may answer the question of how long it will take the U.S. federal government to join with the rest of the world to address the problems created by global warming.

\section{Acknowledgements}

The author would like to acknowledge the assistance of Rodd Bender and Chris Havener in researching this paper.

\section{References}

[1] Karl, T., Hassol, J., Miller, C. \& Murray, L. (eds.). Temperature Trends in the Lower Atmosphere: Steps for Understanding and Reconciling 
Differences, Climate Change Science Program and the Subcommittee on Global Change Research: Washington, DC, 2006.

[2] Parmesan, C. \& Galbraith, H, Observed Impacts of Global Climate Change in the U.S., Pew Center on Global Climate Change: Arlington, VA, 2004.

[3] Trenberth, K. \& Shea, D., Atlantic hurricanes and natural variability in 2005. Geophysical Research Letters, 33, L12704, 2006.

[4] Nesmith, J., Global warming blamed for hurricanes. Philadelphia Inquirer, 23 June 2006, http://www.philly.com/mld/philly/14881262.htm, 2006.

[5] Neikirk, W. \& Martin, A., Energy-saving technologies are years away. The Chicago Tribune, 2 Feb. 2006, p. 4, 2006.

[6] Globe Editorial, Capping the greenhouse. Boston Globe, 4 June 2006, http://www.boston.com/news/globe/editorial_opinion/editorials/articles/20 06/06/04/capping the greenhouse, 2006.

[7] Pew Center on Global Climate Change, Business Environmental Leadership Council, http://www.pewclimate.org/companies_leading the way belc

[8] New State Ice Co. v. Liebmann, 285 U.S. 262, 311 (1932) (Brandeis, J., dissenting).

[9] Massachusetts v. EPA, 415 F.3d 50 (DC Cir. 2005).

[10] New York v. EPA, 443 F.3d 880 (D.C. Cir. 2006).

[11] Choo, K. Feeling the heat. American Bar Association Journal, July 2006, pp. 29-35, 2006. 